\title{
Global Patterns in Students' Views of Science and Interest in Science
}

\author{
Ralf A. L. F. van Griethuijsen • Michiel W. van Eijck • \\ Helen Haste • Perry J. den Brok • Nigel C. Skinner • \\ Nasser Mansour • Ayse Savran Gencer • Saouma BouJaoude
}

(C) Springer Science+Business Media Dordrecht 2014

\begin{abstract}
International studies have shown that interest in science and technology among primary and secondary school students in Western European countries is low and seems to be decreasing. In many countries outside Europe, and especially in developing countries, interest in science and technology remains strong. As part of the large-scale European Union funded 'Science Education for Diversity' project, a questionnaire probing potential reasons for this difference was completed by students in the UK, Netherlands, Turkey, Lebanon, India and Malaysia. This questionnaire sought information about favourite courses, extracurricular activities and views on the nature of science. Over 9,000 students aged mainly between 10 and 14 years completed the questionnaire. Results revealed that students in countries outside Western Europe showed a greater interest in school science, in careers related to science and in extracurricular activities related to science than did Western European students. Non-European students were also more likely to hold an empiricist view of the nature of science and to believe that science can solve many problems faced by the world. Multilevel analysis revealed a strong correlation between interest in science and having such a view of the Nature of Science.
\end{abstract}

Keywords Interest in science $\cdot$ Nature of science $\cdot$ Large-scale studies · International · Comparisons · Empiricism

R. A. L. F. van Griethuijsen $(\bowtie) \cdot$ M. W. van Eijck • P. J. den Brok

Eindhoven School of Education, Eindhoven University of Technology, Eindhoven AZ 5612, Netherlands e-mail: r.a.l.f.griethuijsen@tue.nl

H. Haste

Harvard Graduate School of Education, Harvard University, Cambridge, MA, USA

N. C. Skinner

Graduate School of Education, University of Exeter, Exeter, UK

N. Mansour

Faculty of Education, Pamukkale University, Çamlaraltı Mh. Pamukkale Üniversitesi Pk:20070, Denizli, Merkez/denizli 20070, Turkey

A. Savran Gencer $\cdot$ S. BouJaoude

Center for Teaching and Learning \& Science and Math Education Center, American University of Beirut, Cairo St, Beirut, Lebanon 


\section{Introduction}

Recent international studies have shown low interest in science and technology among secondary school students in many Western European countries (Organisation for Economic Co-operation and Development [OECD], 2007; Sjøberg and Schreiner 2005a). This has led to concern among policy makers about their nation's economy, in which science and technology play an important role, as well as the scientific literacy of their populations (Gago et al. 2004). To make matters worse, student interest in science has gradually eroded over the last 20 to 30 years (Osborne et al. 2003). In contrast, in countries outside Western Europe, such as India, students are generally much more interested in science. In 2006, the Programme for International Student Assessment (PISA) effectiveness study measured both science knowledge and interest in science and included OECD countries (European countries, the USA, Canada, Australia, Japan and South Korea) along with countries outside the OECD. NonOECD countries scored higher than OECD countries on, among other things, general interest in science topics, enjoyment of science learning and motivation to continue studying science (Organisation for Economic Co-operation and Development 2007). In an analysis of the 2006 PISA data, Bybee and McCrae (2011) found that low national average scores on scientific knowledge corresponded with high national average scores for interest in science and vice versa. In other words, in the non-OECD countries, where science education performs the worst, interest in science is the greatest. However, within countries, the better performing students were most interested in science.

Another large international study, the Relevance of Science Education (ROSE) survey, found a similar pattern, with students from industrialised countries, such as Denmark and Norway, scoring lower on interest in science education than students from non-industrialised countries, such as Ghana and Uganda (Sjøberg and Schreiner 2005b). In an analysis of the ROSE data, Sjøberg and Schreiner (2005b) found a strong correlation (-.85) between an aggregate score for interest in science and the state of development of the country as measured by the United Nations Development Index.

Whereas level of development and average scores on the PISA test are both strongly correlated with disinterest in science among young students, they do not explain the mechanisms that drive students away from science. Researchers have posed various potential reasons for this apparent lack of interest in science in Western European countries. Schreiner and Sjøberg (2010) argue that outdated curricula, a shortage of qualified teachers, stereotypically negative images of scientists, lack of role models in science, alternative religious explanations for scientific phenomena, postmodern attacks on science, and a distrust of modern, ambitious, large-scale scientific research are responsible. However, these suggestions do not explain the difference in levels of science interest in developed countries as compared with less developed countries. Curricula in Asia and Africa are often comparable to those in Western Europe, as they are guided and influenced by initiatives and movements in science education that originated in Western Europe and North America. These curricula are likely to be as outdated, or even more so, as their counterparts in Western Europe, although they may not be perceived that way by students. In a similar vein, alternative religious explanations for scientific phenomena are likely to be more prominent in religious societies in Asia and Africa than in secularised Western Europe.

Research has found that the most crucial period in which children make up their opinions about science occurs between the ages of 10 and 14 years (Bennett and Hogarth 2009; Osborne et al. 2003; Speering and Rennie 1996). Students under the age of 10 years are generally 
interested in science, but their interest either remains high or declines as they age. By the age of 14 years, students have mostly made up their minds about science, and their opinions remain relatively stable for the rest of their lives. Several of the explanations given by Schreiner and Sjøberg (2010) for the lack of interest in science focus on why societies in general turn away from science or why older students may choose not to continue their education in science. We believe that these suggestions are unlikely to explain why 14-year-old students have lost interest in science. Students of this age are unlikely to be aware of postmodernist attacks on science or to have developed sophisticated views on how science works or how modern science differs from the science they study at school.

The findings reported in this paper come from a questionnaire study that was part of a large research project named Science Education for Diversity which was funded by the seventh framework programme of the European Union and involved research in the UK, Netherlands, Turkey, Lebanon, India and Malaysia. We chose this diverse selection of countries because relatively few studies outside North America, Australasia and Europe have investigated the way in which students conceptualise the nature of science and whether this is linked to their interest in science. The studies that do exist have been carried out in countries with relatively high levels of economic development, e.g. Japan (Kawasaki 1996), South Korea (Kang et al. 2005) and Taiwan (Liu and Lederman 2002), and did not include less developed countries for which the PISA and ROSE studies revealed high levels of interest in science.

The aim of our research is to find out the effects that particular views of science, gender and age have on different forms of student interest in science. Many studies investigating interest in science have focussed solely on science as it is taught in school and often used a single indicator for interest in science. We believe the use of multiple indicators is more appropriate (Kind et al. 2007). Students have very different experiences outside school as compared to inside the classroom (Akkerman \& van Eijck, 2013). Some students may have positive science experiences outside school (e.g. in science museums), even while indicating disinterest in their school science classes or vice versa. We therefore decided not only to measure interest in science as presented in a school environment but also to measure science as an extracurricular activity and as a future field of employment in order to broaden the analysis. As shown by Hagay et al. (2013), country of residence, age and gender also shape student interest in science, and therefore, these two factors are taken into account in our study.

We begin with a brief review of the literature concerning students' views about the nature of science and the approaches researchers have used to reveal these views. These approaches informed the way in which we carried out our study. In this study, we are mostly interested in how students view science as opposed to whether these views are in line with a contemporary understanding of nature of science (NOS). International differences in interest in science and cross-country comparisons are difficult to investigate and open to many interpretations. Nevertheless, we believe that such research is still valuable in interpreting international differences in science education.

In the background section, we present an overview of nature of science (NOS) in the literature on science education and how views on the NOS have been measured in prior research. We discuss studies that have found differences in views on NOS among people of different nationalities, ages and levels of interest in science. These studies provided examples to guide the way our study was carried out, as discussed in the "Methods" section. The "Results" section presents findings concerning interest in science and views about science and then presents the connection between the two. This paper ends with a discussion of the findings and their possible implications for science education. 


\section{Background}

\section{Nature of Science}

Nature of Science (NOS) refers to how science works, its relationship with society and how scientists collect, interpret and use data in scientific research. The meaning of the term NOS has changed considerably over time and has been interpreted differently by different researchers (Abd-El-Khalick and Lederman 2000). There is, however, a consensus among science education researchers regarding its most important tenets. McComas et al. (2002) made a list of 14 tenets they argued should be part of science education in primary and secondary education. These include, among others, the tentative nature of scientific theories, the way science uses empirical evidence and logic, the absence of a single scientific method by which all scientific research is done, the relationship between laws and theories, the relationship science has with society and the use of creativity and collaboration in science.

Research into NOS started in the 1970s and 1980s, and studies from that era, as well as more recent studies, have repeatedly found that many students hold ideas about science that are incompatible with contemporary ideas about NOS (Abd-El-Khalick and Lederman 2000; Deng et al. 2011). These ideas include, among others, misunderstanding the relationship between scientific laws and theories, thinking of scientific theories as unchangeable and 'true' and not realising that culture and politics can influence science and the direction of scientific research. Prior studies have found that students do not come to a contemporary understanding of how science works on their own and that NOS needs to be explicitly treated in class for students to do so. To address these shortcomings, teaching a modern interpretation of 'how science works' has become part of science curricula in many countries (McComas and Olson 2002). In contrast, the National Research Council in the USA recently decided to not include an explicit teaching of NOS in their framework for K-12 science education (National Research Council [NRC], 2012), and this may eventually impact science education in different countries around the world.

\section{Measurement of NOS Viewpoints}

Several instruments have been developed to investigate students' views about NOS. NOS research has not only been used to find out whether students have a contemporary view of NOS, it has also investigated how students deal with scientific arguments and has been used to place students on a continuum between constructivist and empiricist ${ }^{1}$ views of science (Deng et al. 2011). In broad terms, according to a constructivist perspective on the nature of science, scientific knowledge is constructed by humans and tentative. Consequently, expectations, current beliefs and theories shape the way scientists think of science and how they explain their results. According to an empiricist or positivist perspective, scientific knowledge is taken as solely the result of observation, experimentation or application of a universal scientific method. Hence, from an empiricist perspective, scientific knowledge is usually taken as an unchangeable, absolute truth that results from more or less 'neutral' discoveries. In discussing NOS, most researchers view constructivism as a more contemporary approach.

\footnotetext{
${ }^{1}$ The term empiricist used here is almost interchangeable with the terms positivist and logicopositivist. Positivism and logicopositivism denote a more extreme position on the continuum and therefore have a negative connotation. Therefore, the more neutral term empiricist is used here. Empiricism does not only refer to the use of empiric evidence in science. In a similar way, the term relativism can be considered as a more extreme version of constructivism, which therefore also has a more negative connotation.
} 
Deng et al. (2011) identified unidimensional and multidimensional frameworks used by researchers to categorise students' views of NOS. Both frameworks measure students' standpoints on a continuum ranging from empiricist to constructivist perspectives. In the multidimentional framework, students can be categorised as both empiricist and constructivist at the same time. For example, an constructivist viewpoint can be seen, for instance when the student agrees with the tentative nature of scientific explanations, yet he or she can be catagorised as empiricist for a different tenet, such as the collaborative nature of scientific research (Liu and Tsai 2008). Students also can have different NOS views regarding different domains of science (Schommer-Aikins et al. 2003).

\section{NOS, Interest in School Science and Nationality}

There are indications in the literature that support the hypothesis that interest in science is related to having a particular view on the NOS and to nationality (Jehng et al. 1993; Liu and Tsai 2008). However, the picture emerging is far from clear. The majority of research on NOS has focussed on mistakes students make in their interpretation of science and how science education should correct these views (Lederman 1992). More recently, research has investigated ways in which NOS views vary among different groups of students and professionals and the way in which these views shape their interest in science. This research so far has been limited to college students and other adults and has not investigated students in primary and secondary education.

Several studies have compared the views of students who hold an interest in science and those who do not. In these studies, taking science courses was viewed as a proxy for being interested in science. Liu and Tsai (2008) conducted research with 220 college students, half of them science majors and the other half not and found that science majors did not have more sophisticated views about science than non-science majors. In fact, science majors had more naive views on the theory-laden and cultural aspects of science than their peers. The authors postulated that science students could have adopted their empiricist views of science in class, as secondary science courses generally present science as objective and universal. Another possibility is that students with strong personal epistemological opinions about certainty and objectivity are more likely to choose science as their field of study. A similar study done by Jehng et al. (1993) found that students who major in social sciences, arts and humanities are more likely to believe that knowledge is uncertain than, for example, students in the natural sciences, engineering and business.

Similar patterns have been found for professionals who work in the science domains, such as science teachers. Initially, as reviewed by Abd-El-Khalick and Lederman (2000), teachers' conceptions of NOS were thought to be independent of their educational background in the sciences. Dogan and Abd-El-Khalick (2008), however, found that teachers with postgraduate degrees in science had more empiricist views of NOS than teachers with less formal backgrounds in science. A similar observation was made by Aikenhead (1997), who found that teachers held far more empiricist views of science than their students, and wondered whether this was a result of their science education or whether strongly empiricist students chose to study science. The causal relationship in this matter is still not well understood.

As with interest in science, the relationship between epistemological views of science and culture is one that needs to be further fleshed out. It was initially found that misunderstandings of NOS were universal and no difference was found between different ethnicities or backgrounds (Lederman 1992). More recently, some incidental studies have shown that concepts of NOS differ in different areas of the world. Kang et al. (2005) found that Korean students 
tended to have an instrumentalist view in which science is seen as an instrument to progress and development. A similar observation has been made in Japan (Kawasaki 1996). In a study of over 2000 students from 21 different cities in Turkey, Dogan and Abd-El-Khalick (2008) found that students from regions with lower SES (socioeconomic status), which were also more rural and less Western, had more naive and empiricist ideas of NOS than more Western, urban and high SES students.

\section{Research Questions}

Our study tries to answer three major research questions. The first research question is as follows: Are there differences in interest in science among the students in the six countries that are involved in the study, the UK, Netherlands, Turkey, Lebanon, India and Malaysia? We want to measure interest not only in science as it is taught in school but also in science as an occupation and as an extracurricular activity. Based on studies reviewed in the background section, we hypothesise that students from countries outside Western Europe will hold a greater interest in the various forms of science than Dutch and British students. The second research question is as follows: Do the students from the investigated countries differ in their views of science, in their ideas of what science is, what science can do and how scientists work? We hypothesise on the basis of the reviewed studies that students from countries outside Western Europe will have more empiricist views than students from Western Europe. The third research question is as follows: Is there, across countries, a relationship between interest in science in its various forms and views on science? If the previous two hypotheses are found to be true, our hypothesis is that such a relationship indeed exists and that stronger empiricist views correlate with higher interest in science.

\section{Methods}

Sample

Data were collected from students aged mainly 10 to 14 years, with the selection of students within a country being made by local researchers within the larger project. Attention was paid to school location (rural, urban or suburban) and composition of the school population (religion, ethnicity, socio-economic status) in an attempt to ensure that the samples were reasonably representative of the diversity of students found in the population of the countries. Because entire school classes completed the questionnaire, a small number of students were slightly older or younger than the intended sampling age group of 10 to 14 years. A total of 9,171 students in the age range of 8 to 16 years completed the questionnaire, with $93 \%$ of these in the target age group. Each country had roughly equal numbers of boys and girls, but the percentage of primary and secondary school students varied between countries, as shown in Table 1. In some countries, it was difficult to obtain a diverse sample. The Malaysian sample consisted of school classes from both the peninsula and Borneo. Malaysian society has three major ethnic groups: Malay, Tamil and Chinese. Our sample has a slight overrepresentation of Chinese students versus Malay and Tamil students, as compared to the national census. The Indian sample came from English-language schools in the Mumbai region because it was impractical to sample all over India and translate the questionnaire into each of the many languages used in India. The Indian sample did, however, include students from a variety of socio-economic backgrounds. 
Table 1 Sample properties

\begin{tabular}{llllll}
\hline & $\begin{array}{l}\text { Total number } \\
\text { of students }\end{array}$ & Girls & Boys & $\begin{array}{l}\text { Primary } \\
\text { school } \\
\text { students }\end{array}$ & $\begin{array}{l}\text { Secondary } \\
\text { school } \\
\text { students }\end{array}$ \\
\hline UK & $1,618(17.6 \%)$ & $774(47.9 \%)$ & $843(52.1 \%)$ & $282(17.4 \%)$ & $1,336(82.6 \%)$ \\
Netherlands & $1,239(13.5 \%)$ & $633(51.1 \%)$ & $605(48.9 \%)$ & $137(11.1 \%)$ & $1,102(88.9 \%)$ \\
Lebanon & $1,260(13.7 \%)$ & $615(48.9 \%)$ & $643(51.1 \%)$ & $666(52.9 \%)$ & $594(47.1 \%)$ \\
Turkey & $1,198(13.1 \%)$ & $609(50.8 \%)$ & $589(49.2 \%)$ & $878(73.3 \%)$ & $320(26.7 \%)$ \\
Malaysia & $2,334(25.4 \%)$ & $1,292(55.5 \%)$ & $1,036(44.5 \%)$ & $704(30.2 \%)$ & $1,628(69.8 \%)$ \\
India & $1,522(16.6 \%)$ & $672(44.2 \%)$ & $850(55.8 \%)$ & $883(58.0 \%)$ & $639(42.0 \%)$ \\
Total & $9,171(100.0 \%)$ & $4,595(50.1 \%)$ & $4,566(49.8 \%)$ & $3,550(38.7 \%)$ & $5,619(61.3 \%)$ \\
\hline
\end{tabular}

Instrument

The questionnaire was designed to reveal students' level of interest in science and their views regarding the nature of science. It included, among others, items relating to science as it was taught in school, about potential careers in science and extracurricular activities. The number of items for each of the topics included in the questionnaire is summarised in Table 2. Not all of the items included in the questionnaire are used in the analysis discussed in this paper. Below, the questions concerning interest and views on the Nature of Science are discussed.

A large number of items were included about interest in school science and in other school courses. Students were asked to provide the name of their favourite course and answer questions about their interest in science courses and their interest in having a job related to science later in life. Because we were interested in how students perceived science outside school, a list of extracurricular activities was included for which students could indicate whether they enjoyed doing these activities or not (see Table 4).

Designing questions concerning the nature of science that could be understood by 10 -yearold students posed several challenges. Existing questionnaires, such as the 'Views on the Nature of Science' questionnaire (Lederman et al. 2002) and the 'Views of ScienceTechnology-Society' questionnaire (Aikenhead and Ryan 1992), are designed for older students and were not appropriate for our sample. We included four items about the nature of

Table 2 Composition of the questionnaire

\begin{tabular}{ll}
\hline Topic & Number of items \\
\hline Personal attributes & 17 \\
Favourite course & 7 \\
Least favourite course & 7 \\
Interest in extracurricular activities & 15 \\
Interest in science courses & 8 \\
Opinion on students who like science & 9 \\
Ethics & 5 \\
Nature of science & 16 \\
Opinions on the future & 7 \\
Future job & 8 \\
Personal use of technology & 7 \\
Total & 107 \\
\hline
\end{tabular}


science. These covered the utility of science, the tentative nature of scientific explanations, the creative nature of science and the collaborative nature of scientific research (the statements and their answers can be found in Fig. 4). Because the term 'science' has different connotations in different languages, we also included a question in which students were asked to indicate which of 12 different activities they believed could be thought of as 'science' (see Table 5).

The questionnaire was short enough to be completed by students in $30 \mathrm{~min}$, and most questions used a 3- or 4-point Likert scale to obtain responses. Some open-ended questions were included, most of which could be answered with a one-word answer (e.g. the name of a course). In Netherlands, Turkey and Malaysia, the questionnaire was translated into the appropriate language by local researchers and then translated back to English by their colleagues to check for possible translation errors. The UK, India and Lebanon used an English questionnaire because the language of science instruction is English in these countries. The questionnaire was trialled with a small group of students in each country, and adjustments were made to improve the comprehensibility of several items. For instance, instructions were added on how to answer Likert-type scale questions, because it turned out that several students had problems understanding these questions. The questionnaire was completed individually by students during science classes in the presence of a researcher who was able to offer clarification if needed.

Analysis

Descriptive analysis, factor analysis and multilevel analysis were used to investigate students' levels of interest in science and their different views of science.

\section{Factor Analysis}

Exploratory factor analysis was used to reduce the large numbers of items to a smaller set of factors to make international comparison more straightforward. Factor analysis was carried out using the entire sample. The factors that appeared were checked for stability in single countries by running the factor analysis again with national samples. The same factors appeared for the national samples.

The factor analysis was performed on questions about interest in extracurricular activities, interest in school science, the meaning of the word science and the nature of science. Factor analysis was carried out with the computer programme SPSS. Principal Component Analysis was used with varimax rotation with Kaiser normalisation. Only those factors with an eigenvalue over 1 were extracted.

Factor scores for interest in school science and interest in a science-related career were created using the items listed in Table 3. These were all Likert scale items, apart from two questions asking students to indicate favourite and least favourite courses. Because different science courses were offered by schools in each of the countries, answers to this question were coded as either belonging or not belonging to the realm of science and mathematics. The outcomes of this analysis in Table 3 show how much each item contributes to the factors. Completely overlapping factors would result in a score of 1 or -1 , whereas those having nothing in common with the factor have a score of 0 . Only factor scores over 0.4 or under -0.4 are given in Table 3 . The factor analysis created two different factors, one relating to interest in school science and the other to a career in science. For each factor, Cronbach's alpha was calculated based on the items that contributed over 0.4 to the factors. Several of the values calculated for Cronbach's alpha are below the acceptable values of 0.7 or 0.6 . This is mainly due to the small number of items that 
Table 3 Factors for interest in school science and science jobs

Rotated Component Matrix

\begin{tabular}{|c|c|c|}
\hline & \multicolumn{2}{|l|}{ Factor } \\
\hline & $\begin{array}{l}1 \text { Interest in school } \\
\text { science }\end{array}$ & $\begin{array}{l}2 \text { Interest in } \\
\text { science jobs }\end{array}$ \\
\hline I like all science lessons in school & .728 & \\
\hline I like some science lessons but not all of them & -.595 & \\
\hline I don't like any science lessons & -.552 & \\
\hline I would like a job where I can discover and invent new things & & .872 \\
\hline I would like a job related to science and technology & & .829 \\
\hline Favourite course & .446 & \\
\hline Least favourite course & -.515 & \\
\hline Cronbach's alpha & .502 & .673 \\
\hline Spearman Brown Lengthening needed to reach 0.7 & 2.31 & 1.13 \\
\hline
\end{tabular}

Factor analysis on several items related to interest in school science. Two factors were identified that explained $47.4 \%$ of all variance. For the first three items, students could indicate whether they found the statements to be very true, a bit true or not true. For the fourth and fifth statements, students could indicate whether they would like something very much, a little or not. The final two items were coded as either a STEM course or not

contributed to the factors. The Spearman Brown prediction formula shows that for these factors, slightly increasing the number of items would lead to acceptable values for Cronbach's alpha. Both the factors for interest in school science and interest in science jobs had normal distributions with skewness values of -0.257 and 0.081 respectively.

To construct factors indicating the extent to which students were interested in various extracurricular activities, we analysed the 15 activities listed in Table 4 . For each of these activities, a student could indicate whether they enjoyed or did not enjoy them. As shown in Table 4, three underlying factors were revealed: interest in science-related activities, interest in technology-related activities and interest in domestic activities. Many of the science-related activities concern learning about science, whereas technology activities are generally more related to practical activities. The factors for technology activities and domestic activities were normally distributed (the values for skewness were -.188 and -.107 respectively). The distribution for the science activities was slightly negatively skewed with a value of -.404 . This is still within acceptable boundaries for a normal distribution. There were no outlying factor scores.

The factor analysis of the items concerned with whether different activities were part of the realm of science revealed three underlying factors: natural science, social science and applied science, as detailed in Table 5. The distribution of the applied science factor was normal (skewness of -.027), whereas the social science factor was skewed slightly positively (skewness value of .230), and the natural science factor was skewed slightly negatively (skewness value of -.772). Values for skewness were within acceptable boundaries for a normal distribution. There were no outlying factor scores.

\section{Multilevel Analysis}

Multilevel modelling using the software package MLwiN Version 2.02 (Rasbash et al. 2005) was used to investigate the relationship between the different factors. 
Table 4 Factors for interest in extracurricular activities

Rotated Component Matrix

Component

\begin{tabular}{lll}
\hline 1 Interest in & $\begin{array}{l}2 \text { Interest in } \\
\text { technology } \\
\text { science activities }\end{array}$ & $\begin{array}{l}\text { Interest in } \\
\text { domestic } \\
\text { activities }\end{array}$
\end{tabular}

Going to science museums

.646

Watching TV about animals and nature

.640

Finding out how our bodies work

Watching TV about space and planets

.662

Finding out about new inventions and discoveries

.544

Helping to look after people when they are sick

.521

Using new machines and technology

Fixing things when they break

Thinking about ways I and my family can help the environment

.640

Cooking and preparing food

Making things out of wood or metal

Making or altering clothes

Talking to my parents about science

Watching TV about natural events, e.g. volcanoes

.668

Talking to my friends about science

.720

Cronbach's alpha

.852

Spearman Brown Lengthening needed to reach 0.7
.641

1.31
.446

2.90

Factor analysis for 15 items that all expressed an interest in doing a particular activity. Students could indicate they liked activities very much, a bit or not at all. Three factors were identified that explained $56.5 \%$ of all variance

In this study, the factors and variables for having a particular view of science (natural, social and applied science, and the four NOS tenets) were used to explain variance in the various forms of interest (interest in school science, science jobs, science, technology and domestic activities). Age and gender are known to be related to interest in science, and the national samples differed in the number of boys versus girls and primary versus secondary school students. Therefore, gender and school type (primary and secondary education, which correspond to younger and older age groups) were included in the multilevel analysis to correct for these influences.

Multilevel analysis makes use of statistical hierarchical linear regression models with different levels and provides a measure of the percentage of variance explained at each level. The models in this study use three different levels: student, school and country. Each student is situated in a school within a particular country. School and country levels have an impact on an individual student's level of interest in science because students in the same school or country will experience similar cultural and educational experiences. For instance, all students from one particular school where teachers succeed in making their science lessons interesting will score higher on average than students from a school in which science is taught in an uninspiring way. 
Table 5 Factors for Nature of Science

Rotated Component Matrix

\begin{tabular}{llll}
\hline & Factor & & \\
\cline { 2 - 3 } & 1 Natural Science & $\begin{array}{c}\text { 2 Social } \\
\text { Science }\end{array}$ & $\begin{array}{c}\text { S Applied } \\
\text { Science }\end{array}$ \\
\hline Making music & & .496 \\
Looking at fossils and dinosaurs & & .629 \\
Finding out how to cure diseases & .588 & .469 \\
Exploring space & .730 & .563 \\
Finding out about climate change & .611 & .711 \\
Digging up old cities and temples & & .694 \\
Healing people who are sick & & .529 \\
Farming & & .454 \\
Building a bridge & & .770 \\
Finding out why some countries are poor and some rich & & .631 \\
Finding out why some people learn things more easily than others & & .544 \\
Reading about people in the past who discovered or invented things & & .671 \\
Cronbach's alpha & & .622 \\
Spearman Brown Lengthening needed to reach 0.7 & .604 & 1.14 \\
\hline
\end{tabular}

Factor analysis on 12 items on which students indicated whether each belonged to the realm of science or not. Students could indicate whether they believed something was always, sometimes or never part of science. Three factors were identified that explained $47.5 \%$ of all variance

Two models were used in this analysis: an 'empty model', in which no explanatory factors were used, and a 'significant model', which included those factors that made a significant contribution to the explanatory power of the model. The empty model assumes that interest is similar for all students, a prediction that is at odds with the real score and therefore there is much unexplained variance. The significant model, which predicts different scores for each student based on their statistically significant characteristics, gives a better description of reality. A reduction in unexplained variance shows the improvement of the predictive power of the model.

Effect sizes were calculated in order to make the found coefficients of factors, four Likerttype scales and dichotomous comparative. Effect sizes were calculated by multiplying the coefficients by the standard deviation of the corresponding factor, scale or value divided by the standard deviation of the corresponding interest factor, as described by Snijders and Bosker (1999).

\section{Results}

Interest in Science (Research Question 1)

Student responses to questions asking them to list their favourite and least favourite school subject are summarised in Table 6. Students from India were the most likely to have written down the name of a science or mathematics course as a favourite class; Dutch and English students were the least likely to do so. Nearly half of the English students and only a quarter of 
Table 6 Favourite and least favourite courses

\begin{tabular}{lllllll}
\hline & Netherlands & UK & Lebanon & Turkey & Malaysia & India \\
\hline Science or mathematics as a favourite course & $22.5 \%$ & $29.6 \%$ & $56.0 \%$ & $52.8 \%$ & $48.3 \%$ & $60.5 \%$ \\
Science or mathematics as a least favourite course & $39.0 \%$ & $48.8 \%$ & $37.8 \%$ & $41.5 \%$ & $44.7 \%$ & $27.0 \%$ \\
\hline
\end{tabular}

Mathematics, Chemistry, Physics, Biology, Technology, Computer Science and Geography were counted as science and mathematics courses

the Indian students indicated that a science subject or mathematics was their least favourite subject. The factor related to interest in school science that emerged from the factor analysis provides further evidence for a division between the two Western European countries and the other four countries. Figure 1 shows how the mean country scores on the 'interest in school science' factor deviate from the international mean, which is set at 0 . The factor related to interest in a science career shows even larger differences between the countries.

The next question to answer was whether, next to this greater interest in science in school, there was also a greater interest in science outside school in countries outside Western Europe. Factor analysis also showed that students from Lebanon, Turkey, Malaysia and India displayed a greater interest in extracurricular activities related to science than Dutch and English students (Fig. 2), with students from India again giving the most positive scores. Interest in more practical activities related to technology and in domestic activities, such as preparing food, showed similar levels in all countries.

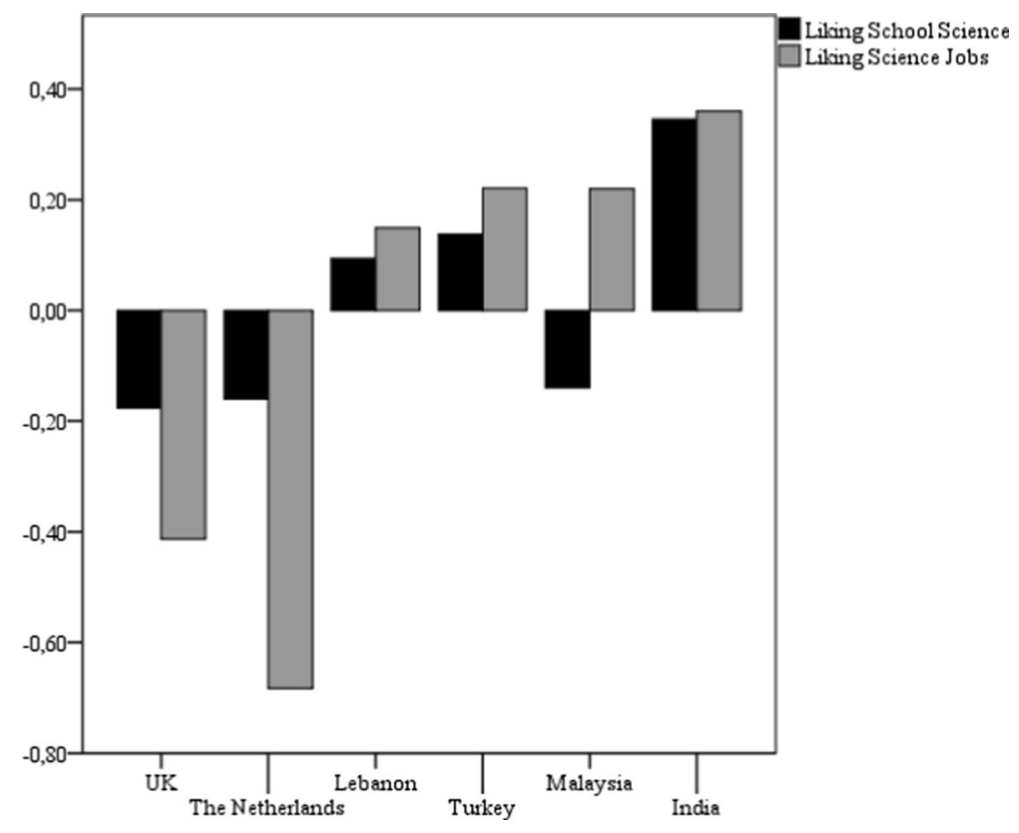

Fig. 1 Interest in school science and a career in science. Mean country scores for interest in school science and interest in a career in science. The mean for the entire sample of students is set at 0 and national variations around the international mean are shown. A higher score indicates a greater interest 


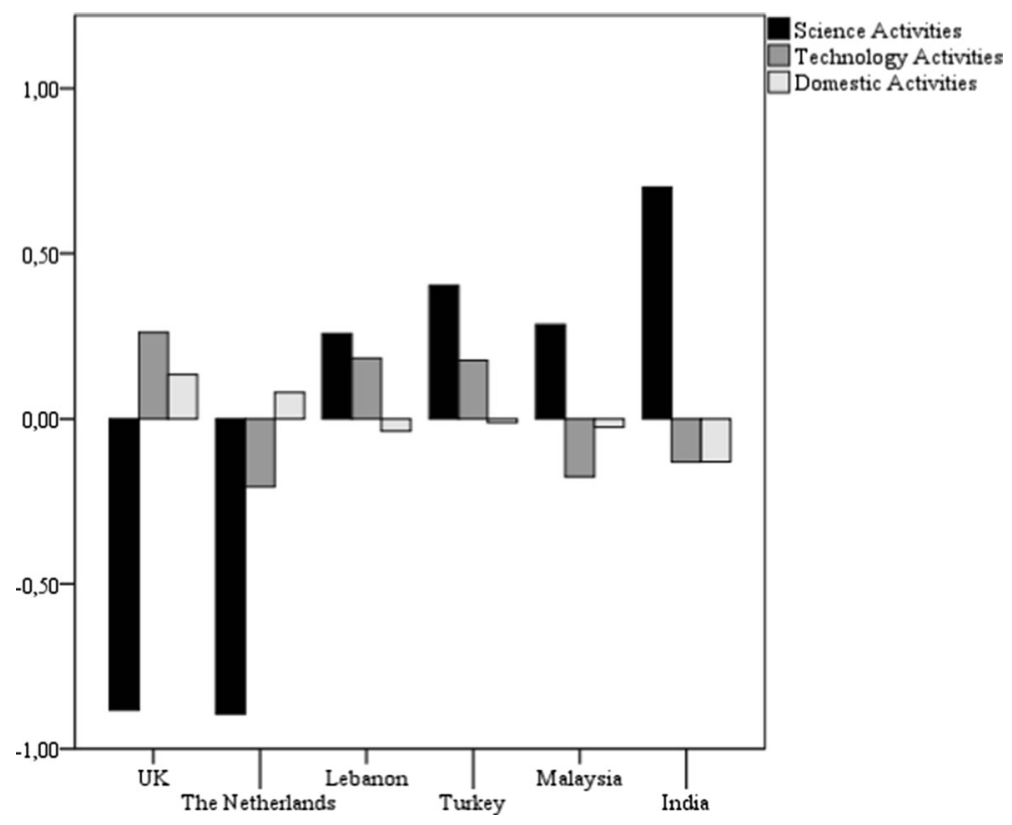

Fig. 2 Interest in extracurricular activities. Mean country scores for the factors science, technology and domestic activities. The mean for the entire sample of students is set at 0 and national variations of the international mean are shown. A higher score indicates a greater interest

Students' Views on Science (Research Question 2)

Mean country scores on the three factors show how students in different countries differ from each other in their views of what does and does not belong to the realm of science. Figure 3 shows whether, on average, students from the six countries are more (higher score) or less likely (lower score) to believe that natural science, social science and applied science are part of science as a whole. Dutch and Turkish students generally have a broader interpretation of the word 'science' than students in the UK and Lebanon. The scores for applied science do not adhere to the general pattern formed by the natural and social science scores. Dutch students do not consider applied science to be part of science but generally have a broad view of science that includes many of the natural and social science items. The opposite is true for India. Here again, a division can be made between Western Europe and the other countries.

Students were asked four questions concerning the tenets of nature of science: two questions about how science works and two about the work of a scientist. Figure 4 shows the percentage of students who chose a particular answer on a 4-point Likert scale. Large differences can be observed between the countries. The questions about science itself showed that more students from the four countries outside Western Europe held empiricist views about NOS. In India, $60 \%$ of all students answered that science can solve most problems people face in their life and $43.1 \%$ of all students believed that science tells us what is completely true. Only a small percentage of Dutch and British students gave these answers. There were small differences in the answers to the item relating to whether scientists work in groups or alone. Turkish, Malaysian and Indian students viewed science as a more creative and less 'fact-based' activity than Dutch, British and Lebanese students. 


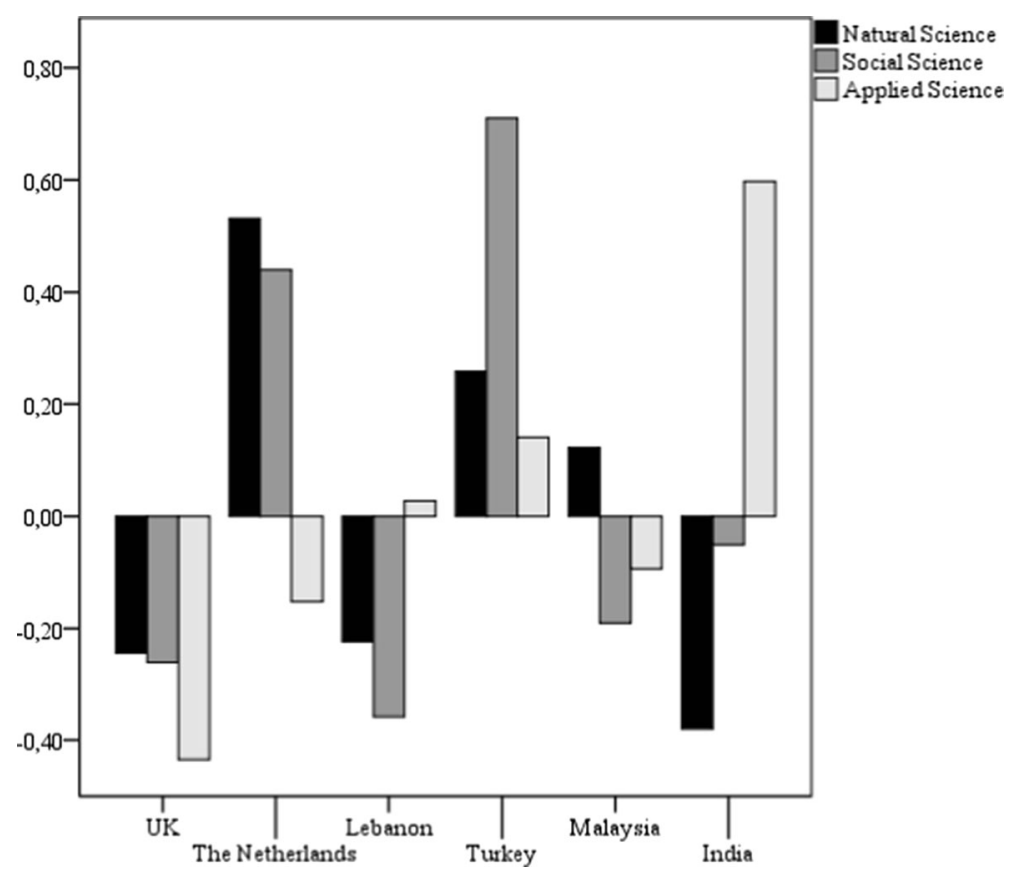

Fig. 3 Interpretation of the word science. Mean factor scores per country for the factors natural science, social science and applied science. The mean for the entire sample is set at 0 and the national variations on this mean are shown. A positive score indicates a greater likeliness that something is considered to be science

The Relationship Between Students' Views of Science and Their Interest in Science (Research Question 3)

Multilevel modelling was used to investigate the relationship between students' interest in science and their views on NOS. Tables 7 and 8 show both the empty and the significant model and the reduction in variance between those two models. Reduction in variance is shown at the three different levels and in total, as denoted by the number for $2 \log$ likelihood.

Despite the large country differences found in our previous analyses (Figs. 2, 3 and 4), multilevel analysis showed that most variation for the different forms of interest (58.6 to $94.0 \%$ ) could be identified at the student level (Tables 7 and 8). Interest in school science appears determined for a greater part at the school level than interest in extracurricular activities or interest in jobs in science.

The coefficients of explanatory factors in the significant model show how much higher or lower mean interest scores are for students with particular factor scores or scores on one of the Likert scales. Table 7 shows, for instance, that for each point students score themselves higher on the 4-type Likert scale for science offering solutions to life (Fig. 4), interest in school science would decrease by -0.116 . The corresponding effect size of -0.110 shows that the effect of this scale is about two times that of gender (0.049) and about half that of school level $(-0.201)$.

Across countries, boys appeared more interested in school science, science jobs and activities related to science and technology, and girls showed a higher interest in domestic activities. Primary school students had a higher interest in all activities and in school science, 


\section{Scientific discoveries are ...}

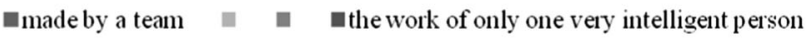

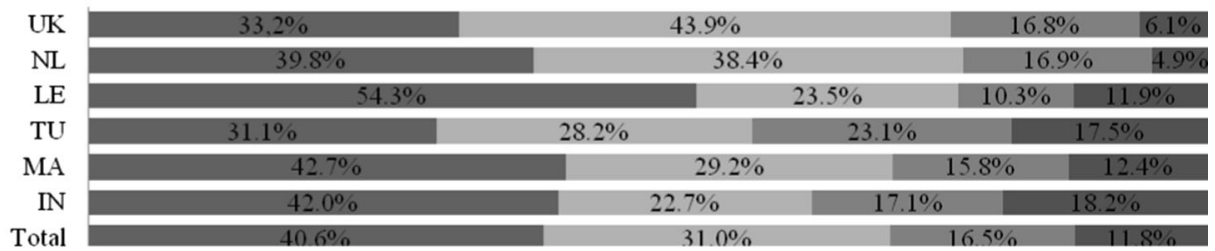

The best scientists...

Use their imagination $\quad$ - $\quad$ stick to the facts

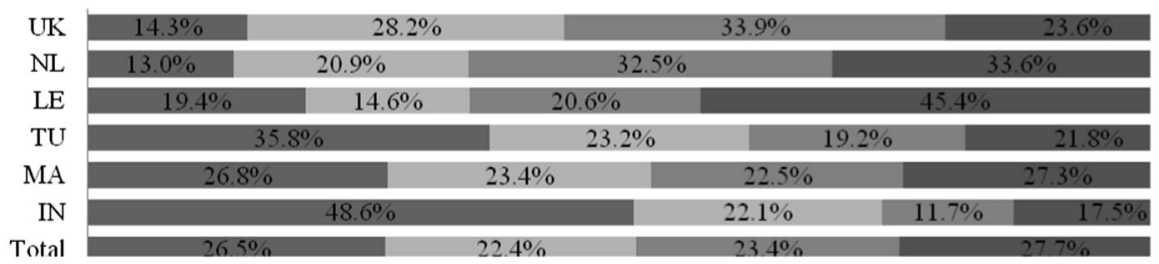

Science can help solve ...

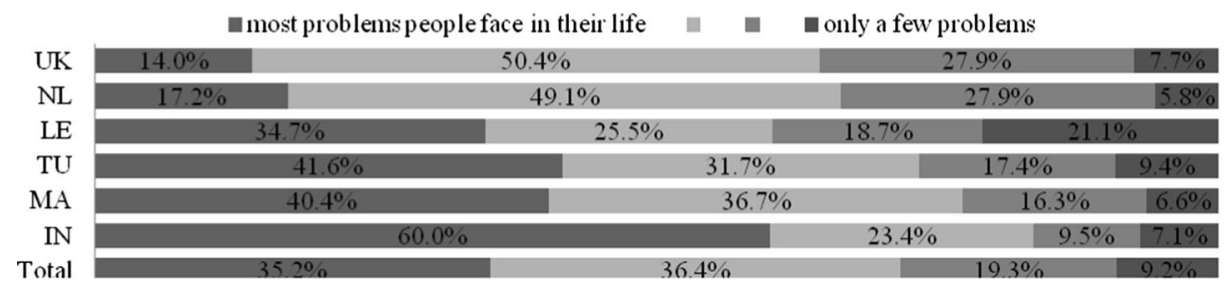

Science is ...

घust the best guess that scientist can make $\quad$ - $\quad$ tells us what is completely true

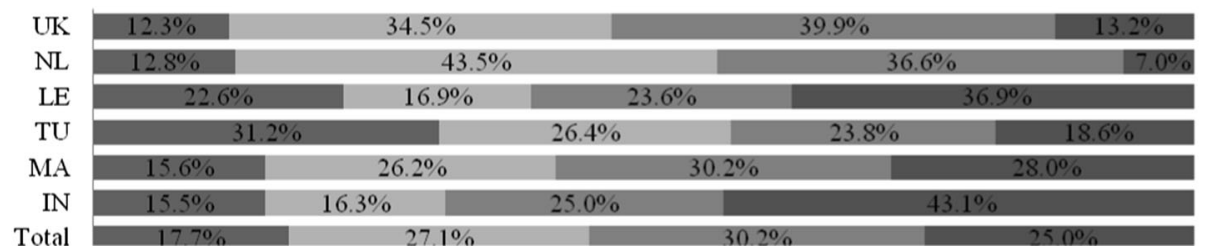

Fig. 4 NOS views of students. Percentages for each of the answers to 4-point Likert scale questions on the nature of science for the six countries. $U K=$ United Kingdom, $N L=$ Netherlands, $L E=$ Lebanon, $T U=$ Turkey, $M A=$ Malaysia, $I N=$ India

but not in science careers, for which primary and secondary school students had similar scores. For example, the effect sizes in Table 7 show that boys scored higher than girls on interest in school science (0.049) and secondary school students scored lower than primary school students $(-0.201)$. The gender difference was relatively small for interest in school science 


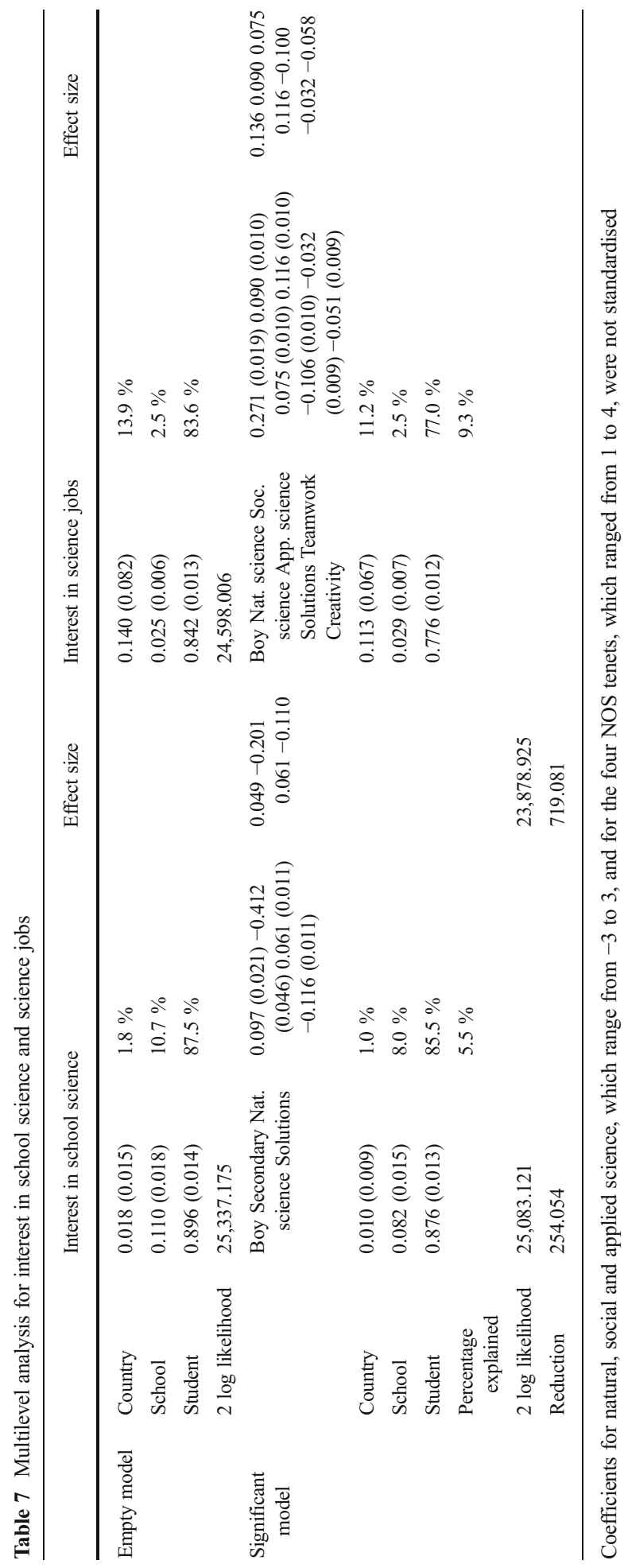




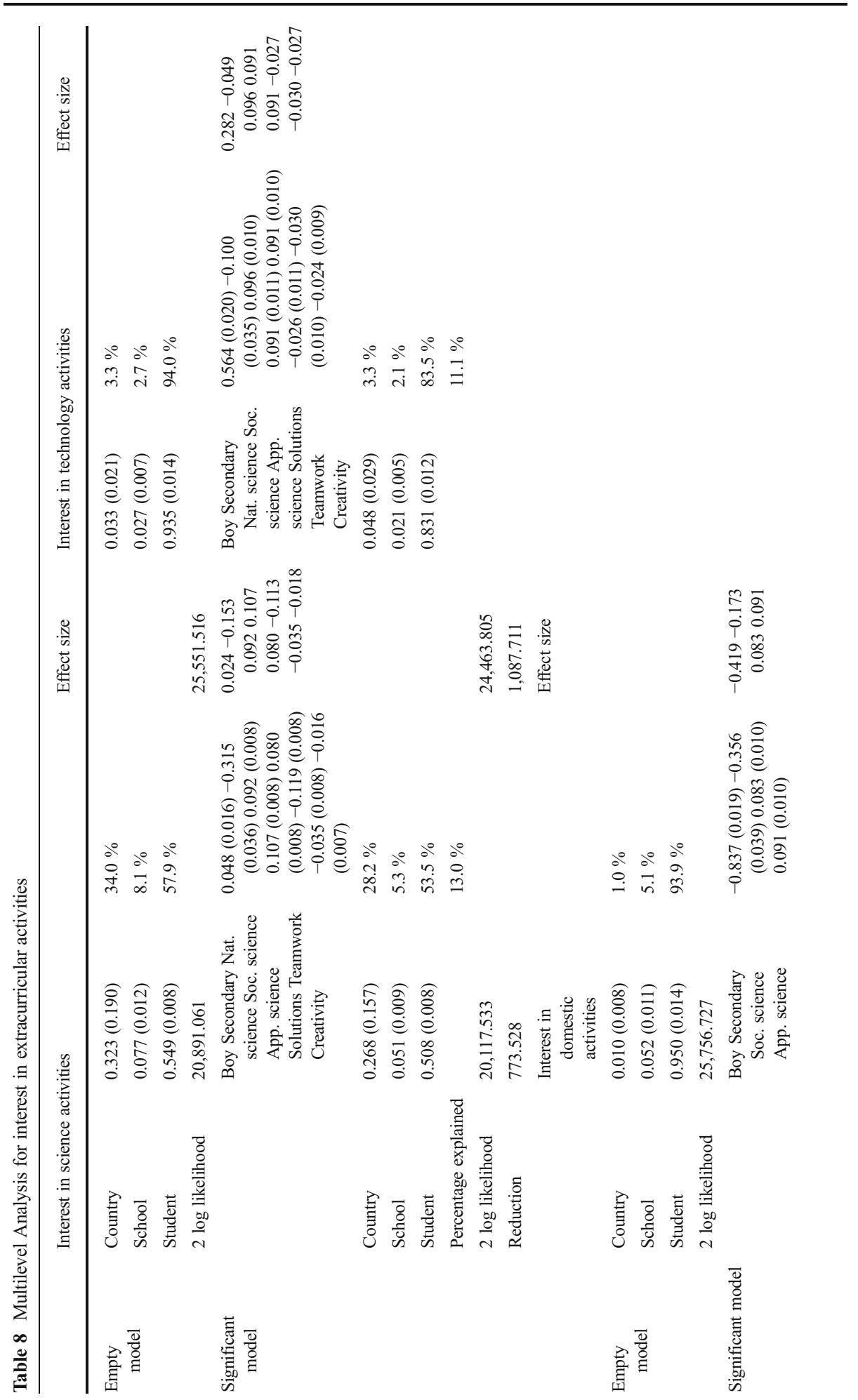




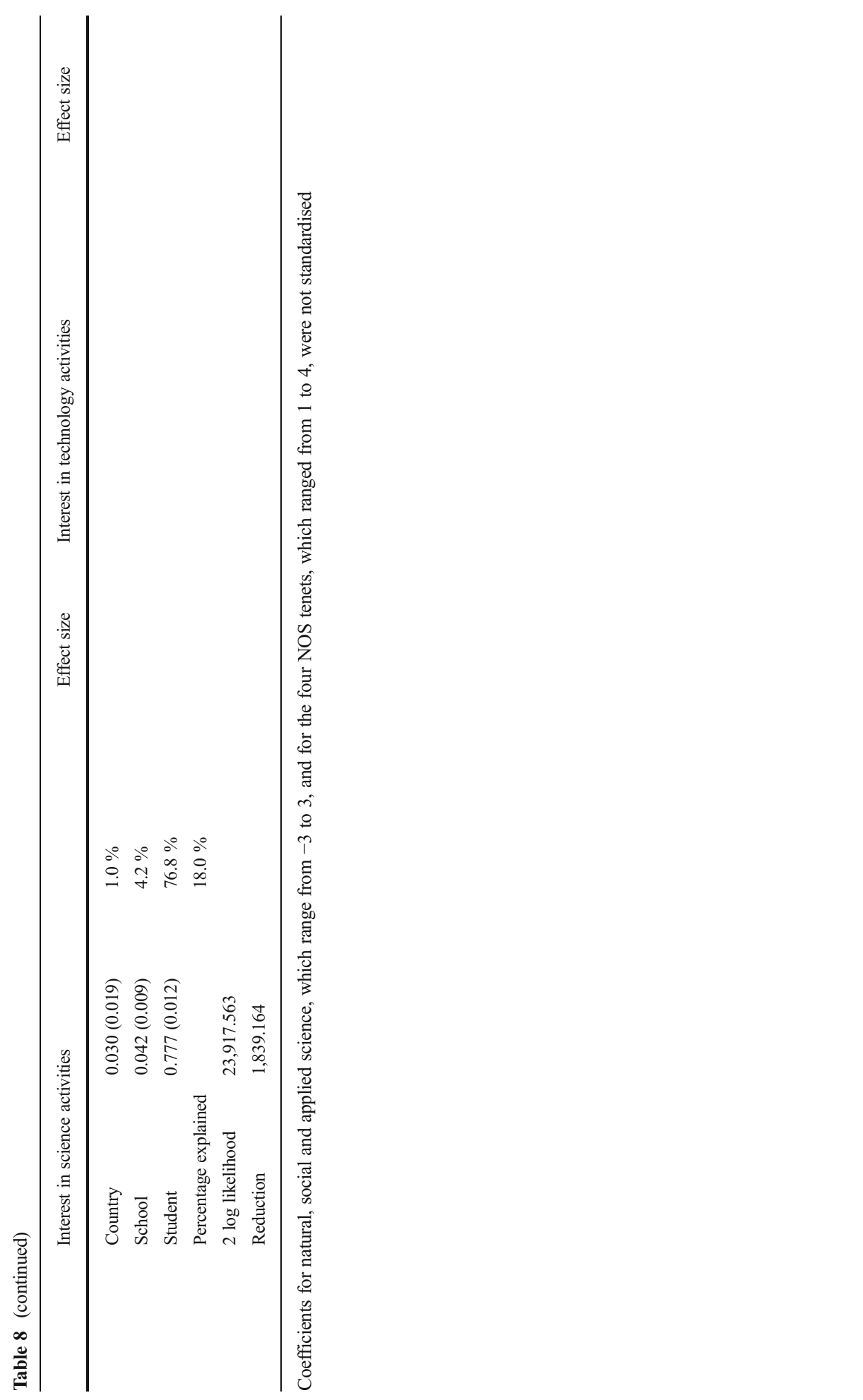


and interest in science activities, but larger for interest in technology activities and careers related to science and technology.

Holding a broader view of science, which includes more aspects of natural, social and applied science, correlated with higher levels of all constructs of interest in science across all countries. Three of the four questionnaire items concerned with the tenets of NOS had an impact on the model. Believing that science is creative, involves teams of researchers and offers solutions to many problems in life correlated with higher levels of interest for all factors except domestic activities.

\section{Discussion and Implications}

The statistics we report showed that students from countries outside Western Europe had greater interest in school science than students within Western Europe. This parallels findings reported in other international studies in which interest in school science was investigated (such as PISA and ROSE). Students outside Western Europe also had a greater interest in careers in science and in extracurricular activities related to science. The greater interest in science courses was not simply caused by an overall greater interest in school courses. Students in Turkey, Lebanon, India and Malaysia preferred science courses over other school courses (Table 6). Similarly, greater interest in extracurricular activities related to science was not caused by an overall greater interest in extracurricular activities. Students from all six participating countries had a comparable interest in activities related to technology, whereas Dutch and British students had slightly more interest in domestic activities.

There were also differences in the ways in which students in different countries perceived science. Large differences were found in the interpretation of what belongs to the realm of science and what does not. Turkish and Dutch students generally had a broader interpretation of the term 'science'. Part of the pattern seen in Fig. 3 may be attributed to the connotations that translated terms for science have in different languages. The Turkish and Dutch words for science appeared to have broader meanings than the English word. However, applied science did not follow the pattern of natural and social science and was more often considered to be part of the science realm by students in Turkey, Lebanon, India and Malaysia than in Netherlands and the UK. This cannot be attributed to language differences, as the UK, Lebanon and India all used questionnaires in the English language and each scored very differently on applied science.

Students outside Western Europe were also more likely to hold empiricist views on several tenets relating to the nature of science. For instance, they had greater confidence in what science can achieve through believing that science can solve most problems in life and that science is completely true. A similar relationship between empiricism and the level of development was reported by Dogan and Abd-El-Khalick (2008) in their study of the views of science held by students living in rural and urban areas of Turkey.

How should the observation that empiricism and nationality seem to be related be interpreted? In our view, there are two possible explanations. The first is that in developing countries, science teachers pay less attention to NOS in their lessons than their Western counterparts and that therefore their students tend to know less about NOS. Since the 1980s, science curricula in European countries, such as the UK (e.g. Solomon 1991) and Netherlands (Eijkelhof and Kortland 1988), have increasingly stressed NOS and the relation between science, technology and society, probably to a greater extent than outside Europe. Students may have changed their views of science according to what they have read in their textbooks and from what they have heard from their teachers. 
The second explanation is that the country differences found in this study are cultural. This means that the prevalence of a particular view of science is a feature of a country that could be related to the state of development of the country or, from a historical perspective, a relatively recent encounter with Western science. The existence of such culturally determined viewpoints is very well possible. It has been argued that the promotion of science as a way of increasing the development of a country led to the instrumentalist view of science that is prevalent among many Asian societies (Kang et al. 2005; Kawasaki 1996). Our finding that the applied aspects of science tend to be far more often considered part of science in non-Western nations, especially in India, confirms this. If instrumentalism is part of a national conceptual idea of science, then the same could be the case for empiricism.

It should be mentioned that we merely measured the positions students took on several key tenets of NOS. We were not explicitly interested in whether or not these students had correct epistemological understandings, something which the questionnaire used in this study could not measure. Generally, science educators consider the constructivist viewpoint as more contemporary and correct than the empiricist viewpoint. Strict empiricist viewpoints, such as believing in science as an absolute truth, are often seen as a 'wrong' interpretation of NOS. This, however, does not imply that the opposite viewpoint, believing that science is 'just the best guess scientist can make', should be interpreted as an informed NOS view. Interviews or additional questionnaire items would be required in order to find out whether or not students had informed beliefs, which would have made the questionnaire longer and more complicated for young students. Nonetheless, some highly empiricist views present among many students stand in contrast with the desired views of NOS that are advocated by science educators and are written down in many policy documents (American Association for the Advancement of Science [AAAS], 1990; AAAS, 2009; National Science Teacher Association [NSTA], 2000).

It is difficult to pinpoint what aspects within a country are causes for different views of science. Is it the educational system present in the country, the state of development, other underlying cultural values or a combination of these three? In the case of Japan, interest in science is as low as in North European countries with a comparable level of development (Sjøberg and Schreiner 2005a), yet an instrumentalist view of science persists (Kawasaki 1996).

Multilevel modelling showed that a model that took account of gender, age and perspectives on science provided a better fit for the findings than an 'empty' model that did not include these factors. However, the various different factors for interest in science have very different associations with background characteristics in the multilevel analysis and show that showing greater interest in school science does not necessarily equate with wanting a career in science or liking activities that are related to science. The model also shows that when students move from primary to secondary school, their interest in school science and in extracurricular activities drops (Tables 7 and 8). However, interest in a science career is not affected by the transition from primary to secondary education. Boys show a greater preference than girls for a career in science and also have a clear preference for hands-on practical activities related to technology. In contrast, gender effects were relatively small for interest in school science and for extracurricular science activities, which are more oriented towards learning than the handson technology activities. Domestic activities, which include gendered activities such as cooking and making clothes, were liked better by girls.

Multilevel analysis also revealed a relationship between student views concerning the nature of science and their interest in science. The statement that science can solve all problems people face in their life had the largest effect in the multilevel models, showing that students who had such a view of science were much more interested in science. Students who believed that scientists had a creative job were also more interested in a career in science than those who 
believed that scientists only dealt with 'facts'. Believing that scientists work in groups or alone had a similarly small effect in the multilevel model. However, not all tenets of NOS correlated with interest in science. Believing in science as an absolute truth did not correlate in any way with students' interest in science. None of NOS tenets were in any way correlated with interest in domestic activities. Students who were interested in science tended to have a slightly broader interpretation of the term 'science' than those not interested in science. This broader concept of science is, however, not limited to a single aspect of science but encompasses natural, applied and social science.

In addition, multilevel analysis showed that, despite large international differences, most variance existed at the individual student level. Interest in school science is also determined to a greater extent by school level than either activities related to science or interest in science jobs. This is understandable because individual teachers have a direct impact on whether students like or dislike courses and have far less influence on individual preferences for extracurricular activities or jobs. The addition of explanatory factors to the models decreased unexplained variance at all three levels, including the country level. Views on the nature of science can thus be considered as an important explanatory factor for international differences in interest in science.

There are some limitations to our study. In some cases, the sampled population was not completely representative of the diversity of students that can be found in one country. One has to take into account that the data from the urbanised Mumbai region might not be generalisable for other regions of India. The Malaysian data has a slight oversampling of Chinese students, who tend to be slightly less interested in science courses than Malay or Tamil students. Furthermore, this study focussed on students in the age group of 10 to 14 years, and the majority of students in the sample were part of that age group. The results of this study cannot be generalised to younger and older age groups. Finally, only quantitative methods were used in this study as we intended to sample a large group of students. More qualitative measures will enable us to learn in more detail why students like or dislike particular aspects of science and how culture affects these views. A more elaborate study involving qualitative research methods could also find out whether there is a relationship between having a contemporary understanding of the nature of science and interest in science.

What are the practical implications of these results for science education? In the multilevel analysis, we found that interest in science jobs and in activities related to science and technology was higher when students believed that scientists are creative people who work in teams and when students believed that applied science was part of science (Tables 7 and 8). Teaching that science is a creative and collaborative endeavour and teaching applied aspects of science have long been goals of science education, and this study reaffirms that this may have a positive impact on various forms of interest in science. Believing that science can offer solutions to all problems in life is strongly correlated with greater interest in science. Application of this finding in the practice of science education is problematic because presenting science as offering solutions in life is at odds with the way science works in reality.

The findings that views on science impact students' interest in science and that these views differ raise further questions for research. The exact nature of the relationship between interest in science and views of science needs to be investigated in greater detail. Furthermore, can different views on science be identified that positively or negatively impact the various forms of student interest in science? When students change their views on science because they receive new information, either in their classes or outside school, does this automatically imply that their interest in science will increase or decrease? It also needs to be established why international differences in NOS views exist. Do students form their ideas about science in their science classes and are these ideas shaped by what their teachers believe or how they 
present science in their classes? Or are there underlying cultural values at play that shape students' views of science? The further elucidation of the dynamic between nationality, views on science and interest in science would be valuable for science education in countries both inside and outside Western Europe. For countries where science generally is not among the most chosen courses in secondary and tertiary education, knowledge about such a dynamic could be used to improve science education and make it more appealing to students. The results from this study suggest that the answer to the problem of decreasing interest in Western Europe would be to develop teaching materials that present scientific research as collaborative, creative and as beneficial for society, rather than simply copying teaching practices from countries where students tend to be more interested in science. Countries outside Western Europe may not face a decreasing interest in science at this moment, but they may in their future. Knowledge of this dynamic can and should be used to make changes in curriculums to make science education more appealing for a new generation of students.

Acknowledgments This publication received funding from the European Union Science in Society Framework 7 Programme (FP7/2007/2013) under grant agreement 244717. We would like to thank the following people for collecting data and contributing to this research project: Roel Janssen, Huseyin Bag, Lindsay Hetherington, Alun Morgan, Keith Postlethwaite, Rupert Wegerif, Ng Swee Chin, Choy Siew Chee, Oo Pou San, Chin Fui Chung, Teh Lee Wah, Sugra Chunawala, Chitra Natarajan and Beena Choksi.

\section{References}

Abd-El-Khalick, F., \& Lederman, N. G. (2000). Improving science teachers' conceptions of nature of science: a critical review of the literature. International Journal of Science Education, 22, 665-701.

Aikenhead, G. S. (1997). Student views on the influence of culture on science. International Journal of Science Education, 19, 419-428.

Aikenhead, G. S., \& Ryan, A. G. (1992). The development of a new instrument-views on science-technologysociety (VOSTS). Science Education, 76, 477-491.

Akkerman, S., \& van Eijck, M.W. (2013). Re-theorising the student dialogically across and between boundaries of multiple communities. British Educational Research Journal, 39, 60-72.

American Association for the Advancement of Science (1990). The liberal art of science: agenda for action. Washington, DC. American Association for the Advancement of Science (2009). The Nature of Science. Project 2061: Benchmarks Online. Retrieved from http://www.project2061.org/publications/bsl/online/ index.php?chapter $=1$

Bennett, J., \& Hogarth, S. (2009). Would you want to talk to a scientist at a party? High school students' attitudes to school science and to science. International Journal of Science Education, 31, 1975-1998.

Bybee, R., \& McCrae, B. (2011). Scientific literacy and student attitudes: perspectives from PISA 2006 science. International Journal of Science Education, 33, 7-26.

Deng, F., Chen, D. T., Tsai, C. C., \& Chai, C. S. (2011). Students' views of the nature of science: a critical review of research. Science Education, 95, 961-999.

Dogan, N., \& Abd-El-Khalick, F. (2008). Turkish grade 10 students' and science teachers' conceptions of nature of science: a national study. Journal of Research in Science Teaching, 45, 1083-1112.

Eijkelhof, H. M. C., \& Kortland, J. (1988). Broadening the aims of physics education. In P. J. Fensham (Ed.), Development and dilemmas in science education (pp. 282-305). London: Falmer Press.

Gago, J. M., Ziman, J., Caro, P., Constantinou, C., Davies, G., Parchman, I., Rannikmäe, I., \& Sjøberg, S. (2004). Europe needs more scientists: report by the high level group on increasing human resources for science and technology in Europe. Retrieved from http://ec.europa.eu/research/conferences/2004/sciprof/pdf/final_en. pdf.

Hagay, G., Baram-Tsabari, A., Ametller, J., Cakmakci, G., Lopes, B., Moreira, A., et al. (2013). The generalizability of students' interests in biology across gender, country and religion. Research in Science Education, 43, 895-919.

Jehng, J.-C., Johnson, S. D., \& Anderson, R. C. (1993). Schooling and students' epistemological beliefs and learning. Contemporary Educational Psychology, 18, 23-35.

Kang, S. J., Scharmann, L. C., \& Noh, T. (2005). Examining students' views on the nature of science: results from Korean 6th, 8th, and 10th graders. Science Education, 89, 314-334. 
Kawasaki, K. (1996). The concepts of science in Japanese and Western education. Science \& Education, 5, 1-20.

Kind, P., Jones, K., \& Barmby, P. (2007). Developing attitudes towards science measures. International Journal of Science Education, 29, 871-893.

Lederman, N. G. (1992). Students' and teachers' conceptions about the nature of science: a review of the research. Journal of Research in Science Teaching, 29, 331-359.

Lederman, N. G., Abd-El-Khalick, F., Bell, R. L., \& Schwartz, R. S. (2002). Views of nature of science questionnaire: toward valid and meaningful assessment of learners' conceptions of nature of science. Journal of Research in Science Teaching, 39, 497-521.

Liu, S.-Y., \& Lederman, N. (2002). Taiwanese gifted students' views of nature of science. School Science and Mathematics, 102, 114-123.

Liu, S.-Y., \& Tsai, C.-C. (2008). Differences in the scientific epistemological views of undergraduate students. International Journal of Science Education, 30, 1055-1073.

McComas, W. F., \& Olson, J. (2002). The nature of science in international science education standards documents. In W. F. McComas (Ed.), The nature of science in science education: rationales and strategies (pp. 41-52). Dordrecht: Kluwer Academic Publishers.

McComas, W. F., Clough, M. P., \& Almazroa, H. (2002). The role and character of the nature of science in science education. In W. F. McComas (Ed.), The nature of science in science education: rationales and strategies (pp. 3-39). Dordrecht: Kluwer Academic Publishers.

National Research Council. (2012). A Framework for K-12 science education: practices, crosscutting concepts and core ideas. Washington D.C.: The National Academies Press.

Organisation for Economic Co-operation and Development. (2007). PISA 2006: Science competencies for tomorrow's world. Volume 1: Analysis. Retrieved from http:/www.oecd-ilibrary.org/education/pisa-2006 9789264040014-en

Osborne, J., Simon, S., \& Collins, S. (2003). Attitudes towards science: a review of the literature and its implications. International Journal of Science Education, 25, 1049-1079.

Rasbash, J., Charlton, C., Browne, W.J., Healy, M., \& Cameron, B. (2005). MLwiN Version 2.02. Centre for Multilevel Modelling, University of Bristol.

Schommer-Aikins, M., Duell, O. K., \& Barker, S. (2003). Epistemological beliefs across domains using Biglan's classification of academic disciplines. Research in Higher Education, 44, 347-366.

Schreiner, C., \& Sjøberg, S. (2010). Science education and young people's identity construction - two mutually incompatible projects? In D. Corrigan, J. Dillon, \& R. Gunstone (Eds.), Re-emergence of values in science curriculum (pp. 231-247). Rotterdam: Sense Publishers.

Sjøberg, S., \& Schreiner, C. (2005a). The ROSE Project: an overview and key findings. Retrieved from http:// www.roseproject.no/network/countries/norway/eng/nor-Sjoberg-Schreiner-overview-2010.pdf

Sjøberg, S., \& Schreiner, C. (2005). How do learners in different cultures relate to science and technology? AsiaPacific Forum on Science Learning and Teaching, 6(2), 1-17. Retrieved from http://www.ied.edu.hk/apfslt/.

Snijders, T. A. B., \& Bosker, R. J. (1999). Multilevel analysis: an introduction to basic and advanced multilevel modeling. London: Sage.

Solomon, J. (1991). Teaching about the nature of science in the British national curriculum. Science Education, $75,95-103$.

Speering, W., \& Rennie, L. (1996). Students' perceptions about science: the impact of transition from primary to secondary school. Research in Science Education, 26, 283-298. 